D S Robinson

Department of Allergy and Clinical Immunology, Leukocyte Biology Section, MRC and Asthma UK Centre in Allergic Mechanisms of Asthma, Faculty of Medicine, National Heart and Lung Institute, Imperial College London, London, UK

Correspondence to: Professor A Barry Kay, Sir Alexander Fleming Building, Leukocyte Biology Section, Imperial College London, South Kensington Campus, London SW7 2AZ, UK a.b.kay@imperial.ac.uk

doi: $10.1136 /$ thx. 2006.073775

Funding: This study was sponsored by the Imperial College Trust Fund.

Competing interests: None declared.

\section{Macrophage enrichment from induced sputum}

Since induced sputum has become a widely used non-invasive method of recovering cells from the surfaces of the bronchial airways, isolating specific cell populations will be necessary in order to learn more about their specific role in innate immunity and inflammation in the airways. Several studies have demonstrated the ability to conduct ex vivo analyses on sputum cells such as phagocytosis and surface marker measurements, but these have not been performed on isolated cell types..$^{1-3}$ This study demonstrates the capability to isolate sputum macrophages from human volunteers in order to advance our understanding of macrophage biology in the airways. To this end, techniques that can enrich and isolate cells without significant activation would prove extremely useful. We compared two common methods for isolating and enriching macrophages in sputum: (1) magnetic bead separation; and (2) Percoll gel density gradient centrifugation. Cell purity and markers of cell activation (mRNA tumour necrosis factor $\alpha$ (TNF $\alpha)$ ) and interleukin$1 \beta(\operatorname{ILl} \beta))$ were measured at various time points in the isolation process.

Nine healthy subjects underwent induced sputum. Sputum collection and sputum processing has been described in detail previously. ${ }^{4}$ For measuring natural cell activation over time, we incubated the processed sputum cells for $3 \mathrm{~h}$ at $37^{\circ} \mathrm{C}$ and analysed mRNA TNF $\alpha$ and ILI $-\beta$ at $0 \mathrm{~h}$ (baseline) and $3 \mathrm{~h}$. In the positive control experiment we incubated the processed sputum cells with $1 \mathrm{ng} / \mathrm{ml}$ LPS (E coli, Sigma). For Percoll (Amersham Biosciences) separation, $600 \mu \mathrm{l}$ of sputum cell suspension $\left(1 \times 10^{6}\right.$ cells/ $\mathrm{ml}$ ) was layered over Percoll solution (42\%) and centrifuged at $560 \mathrm{~g}$ for $10 \mathrm{~min}$. Sputum macrophages were removed and incubated at $37^{\circ} \mathrm{C}$ for $\mathrm{l}, 2$ and $3 \mathrm{~h}$, respectively, and a pre-incubation sample was also collected. The macrophages were further pelleted and stored at $-70^{\circ} \mathrm{C}$. For Dynabead separation, CELLection Pan Mouse IgG Kit (Dynal, Norway) was used for immunomagnetic separation of airway macrophages coated with mouse monoclonal IgG2b HLA-DR antibody (Diatec, Norway). Bead coating and cell isolation was performed according to the protocol from the manufacturer. The isolated cells were incubated at $37^{\circ} \mathrm{C}$ for 1,2 and $3 \mathrm{~h}$, respectively, and a pre-incubation sample was also collected. The samples were further pelleted and stored at $-70^{\circ} \mathrm{C}$. Total RNA was extracted (Qiagen) from all the cell samples and reverse transcription was performed (Superscript III, Invitrogen). We used pre-developed PCR primers and probes for TNF $\alpha$ and the housekeeping gene PGK (Applied Biosystems). Specific primers and probes were designed for
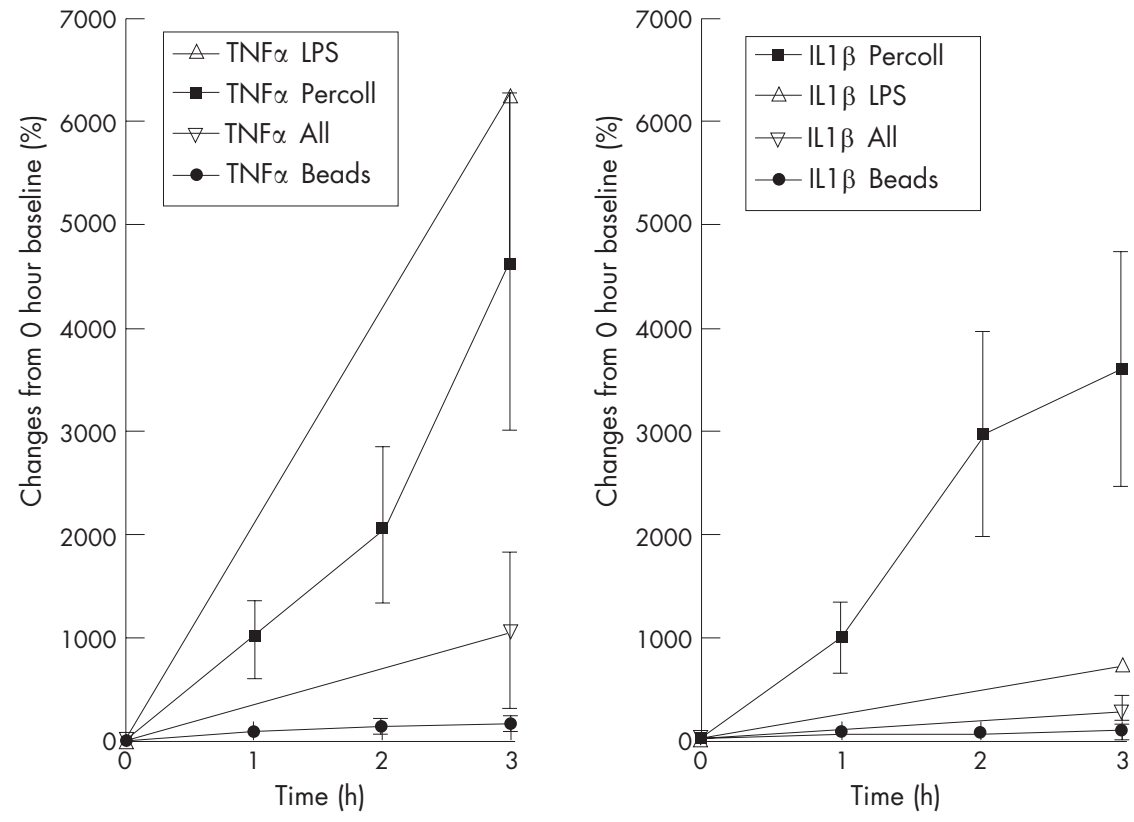

Figure 1 Gene expression of tumour necrosis factor $\alpha(\mathrm{TNF} \alpha)$ and interleukin $1 \beta$ (IL1- $\beta$ ) in airway macrophages in induced sputum. The 0 hour (h) Percoll suspensions are used as baseline for $1 \mathrm{~h}, 2 \mathrm{~h}$ and $3 \mathrm{~h}$ Percoll suspension (TNF $\alpha$ or IL1 $\beta$ Percoll, $n=7$ ). The Dynabeads 0 hour suspension are used as the baseline sample for $1 \mathrm{~h}, 2 \mathrm{~h}$ and $3 \mathrm{~h}$ Dynabeads suspensions (TNF $\alpha$ or IL $1 \beta$ beads, $\mathrm{n}=6$ ). In addition, gene expression in the whole cell population is measured at $0 \mathrm{~h}$ and at $3 \mathrm{~h}$ with $(\mathrm{n}=1)$ or without $(n=5)$ addition of lipopolysaccharide (LPS). The data are presented as mean (SE).

ILl $\beta$ using ProbeLibrary (Exiqon ProbeLibrary). Quantification of mRNA was performed using the ABI Prism 7700 (Applied Biosystems), and the relative standard curve method was used to calculate the relative gene expression.

The results show that the median (range) proportion of macrophages in the pre-isolation sputum sample was $61(34-70) \%$. Bead isolation produced 99 (95-99)\% macrophage purity compared with $88(85-94) \%$ with Percoll isolation mRNA expression of TNF $\alpha$ and ILI $\beta$ was measured as markers of cell activation in airway macrophages (fig 1) before and after Percol isolation, Dynabead isolation, no isolation and lipopolysaccharide $(1 \mathrm{ng} / \mathrm{ml}$ ) stimulation (positive control). Levels of mRNA TNF $\alpha$ and ILI $\beta$ were significantly increased as early as $2 \mathrm{~h}$ using Percoll isolation compared with $0 \mathrm{~h}$ baseline $(p=0.02)$ and bead isolation $(p<0.01)$. For bead isolation, mRNA TNF $\alpha$ and ILI $\beta$ expression were unchanged throughout the isolation period compared with baseline. At $3 \mathrm{~h}$ after bead isolation, macrophage mRNA TNF $\alpha$ expression remained near baseline levels whereas Percoll-separated macrophages showed increased activation near positive control (lipopolysaccharide) levels.

The results from this study show that sputum macrophages can be successfully isolated and enriched with a high degree of purity. Furthermore, the magnetic bead isolation technique results in higher macrophage purity and significantly less cell activation than the Percoll isolation technique. As more researchers begin to use individual sputum cell populations to describe airways cellular phenomena, data presented here will provide important technical information to achieve those research aims.

\section{Acknowledgement}

Financial support was kindly provided by the Research Council of Norway, The Working Environmental Fund, Confederation of Norwegion Enterprise and NIHNHLBl grant no ROl-HL080337.
Liv I B Sikkeland

Centre for Occupational and Environmental Medicine Rikshospitalet-Radiumhospitalet Medical Center, Oslo and Department of Respiratory Medicine, Faculty Division Rikshospitalet, University of Oslo, Norway

Johny Kongerud

Department of Respiratory Medicine, RikshospitaletRadiumhospitalet Medical Center, Oslo and Departmen of Respiratory Medicine, Faculty Division Rikshospitalet, University of Oslo, Norway

Astrid M Stangeland Department of Respiratory Medicine, Faculty Division Rikshospitalet, University of Oslo, Norway

Terie Haug

Centre for Occupational and Environmental Medicine, Rikshospitalet-Radiumhospitalet Medical Center, Oslo,

Norway

Neil E Alexis

Centre for Environmental Medicine, Asthma and Lung Biology, University of North Carolina, Chapel Hill, North Carolina, USA

Correspondence to: Dr Liv I B Sikkeland, Centre for Occupational and Environmental Medicine, Rikshospitalet-Radiumhospitalet Medical Center N-0027 Oslo, Norway; liv.sikkeland@ rikshospitalet.no

Competing interests: None.

\section{References}

1 Alexis NE, Lay JC, Zeman K, et al. Biological material on inhaled coarse fraction particulate matter activate airway phagocytes in vivo in healthy volunteers. J Allergy Clin Immunol 2006;1 17:1396-403.

2 Alexis NE, Lay JC, Zeman KL, et al. In vivo particle uptake by airway macrophages in healthy volunteers. Am J Respir Cell Mol Biol 2006:34:305-13. doi: 10.1136/thx.2006.073544 
3 Maestrelli $\mathbf{P}$, De Fina $O$, Bertin $T$, et al Integrin expression on neutrophils and mononuclear cells in blood and induced sputum in stable asthma. Allergy 1999;54:1303-8.

4 Alexis NE, Lay JC, Almond M, et al. Inhalation of low-dose endotoxin favors local $\mathrm{TH} 2$ response and primes airway phagocytes in vivo. J Allergy Clin Immunol 2004;114:1325-31

\section{Lymphangioleiomyomatosis- presence of receptor tyrosine kinases and the angiogenesis factor VEGF-A as potential therapeutic targets}

Lymphangioleiomyomatosis (LAM) is a rare systemic disorder in women occurring either sporadically (sporadic LAM) or in association with tuberous sclerosis (TS-LAM). It is caused by proliferating smooth muscle-like LAM cells, which lead to a progressive cystic destruction of the lungs and abdominal tumours (renal angiomyolipomas and/or axial lymph node lesions). LAM cells express receptors for oestrogen and progesterone and stain positive for HMB-45, an antibody against the melanoma-related antigen. ${ }^{1}$ LAM fulfils the criteria of a neoplastic disease with enhanced proliferation ${ }^{2}$ metastasising processes, increased migratory activity and invasiveness of LAM cells. ${ }^{4}$ Currently, an effective treatment interfering with these processes does not exist. Growth factors such as platelet-derived growth factor (PDGF) and epidermal growth factor (EGF) have been identified to enhance LAM and renal angiomyolipoma cell proliferation in vitro. ${ }^{25}$ Whether LAM cells express growth factorassociated receptor tyrosine kinases and the angiogenesis factor vascular endothelial growth factor-A (VEGF-A), which represent promising targets of small-molecule and antibody therapy in neoplastic diseases, is currently unknown.

We studied immunohistochemically the expression of the following proteins by LAM cells in 10 formalin-fixed and paraffin-embedded LAM specimens: epidermal growth factor receptor (EGFR; PharmDx Kit, Dako, Hamburg, Germany), platelet-derived growth factor receptor $\alpha$ (PDGFR- $\alpha$; rabbit polyclonal, Dianova, Hamburg, Germany), human epidermal growth factor receptor-2 (HER2; HercepTest, Dako), VEGF-A (clone VGl identifying the VEGF-A isoforms $\mathrm{VEGF}_{121}, \mathrm{VEGF}_{165}$ and $\mathrm{VEGF}_{189}$, DCS, Hamburg, Germany) and c-KIT (CD117; rabbit polyclonal, Dako). Staining procedures were carried out according to the manufacturer's instructions, and appropriate positive and negative controls were used. A semiquantitative scoring system of the immunohistochemical reactions for all receptor tyrosine kinases, the hormone receptors and VEGF-A was applied as follows: negative, no reaction or percentage of positive cells $<5 \%$; $1,5-25 \%$ positive cells; $2,26-$ $50 \%$ positive cells; $3,51-75 \%$ positive cells; 4 , $>75 \%$ positive cells; + , weak staining intensity; ++, moderate staining intensity; ++, strong staining intensity. Histological severity of lung destruction was assessed using the LAM histological score. ${ }^{6}$ The assessment of the LAM histological score and the immunohistochemical stainings was performed independently by two histopathologists (KE and MA). Only morphologically clear-cut, HMB-45 positive LAM lesions (nodules, cysts and diffuse LAM cell proliferations) were taken for analysis. All final decisions were made by consensus. Additionally, EGFR gene copy number per LAM cell nucleus was investigated by one histopathologist (SL) using fluorescence in situ hybridisation (FISH; LSI EGFR SpectrumOrange/ CEP 7 SpectrumGreen probe, Vysis, Abbott Laboratories, Wiesbaden, Germany). The study

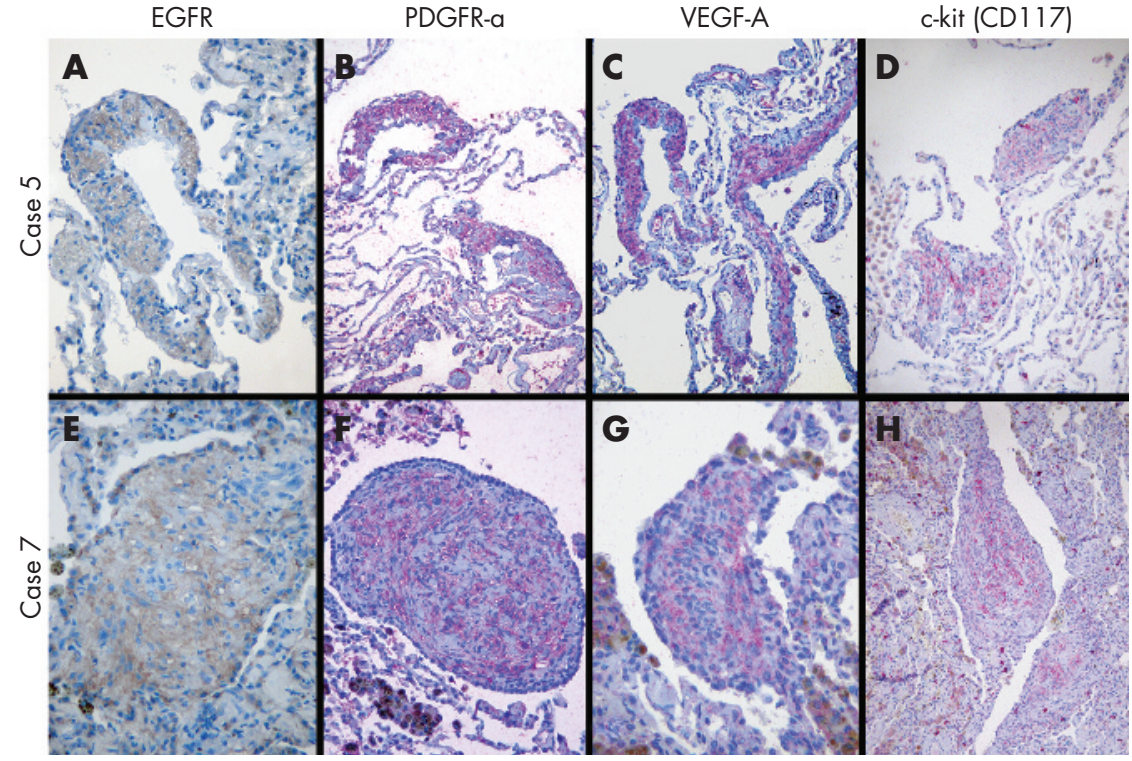

Figure 1 Expression of epidermal growth factor receptor (EGFR), platelet-derived growth factor receptor $\alpha$ (PDGFR- $\alpha$ ), vascular endothelial growth factor-A (VEGF-A) and c-KIT (CD117) in lung lymphangioleiomyomatosis (LAM) lesions. The panel shows two pulmonary LAM specimens (case 5, $A-D ;$ case $7, E-H)$. Case 5 (A-D) represents predominant cystic and diffuse proliferating LAM lesions, whereas case $7(E-H)$ represents predominant nodular growth pattern. The cases show a variable expression of EGFR, PDGFR- $\alpha$, VEGF-A and c-KIT (CD117).

was approved by the local ethics committee and written informed consent was obtained from al participants or their close relatives.

In all specimens, LAM lesions were consistently positive for PDGFR- $\alpha$ and VEGF-A. EGFRpositive LAM cells were observed in seven specimens. No amplification or higher polysomy of the EGFR gene was detected. In addition to cKIT-positive mast cells, which were sporadically present in LAM lesions and the surrounding lung tissue, LAM cells themselves were found to be positive for c-KIT in six of the specimens. HER2 was negative in all specimens (fig 1). For details, see supplementary table available online at http:/ www.thorax.bmjjournals.com/supplemental.

We demonstrated that PDGFR- $\alpha$, EGFR, c-KIT and VEGF-A as targets of currently available compounds are expressed by LAM cells. These findings imply further research in the field of small-molecule and antibody therapy in LAM.

\section{Acknowledgements}

We thank Professor H Morr, Dr J Linke, Dr J Galle, Dr C Smaczny and Dr M Choschzick for providing us with the tissue samples. We also thank Ralf Lieberz and his team for the excellent technical assistance.

Henrik Watz*

Pulmonary Research Institute, Hospital Grosshansdorf Center for Pneumology and Thoracic Surgery, Grosshansdorf, Germany

Knut Engels*

Department of Pathology, University Clinic Frankfurt, Frankfurt, Germany

Siegfried Loeschke

Department of Pathology, Resea Borstel, Germany

Michael Amthor

Department of Pathology, Hospital Rotenburg Rotenburg, Germany

Detlef Kirsten, Helgo Magnussen

Hospital Grosshansdorf, Center for Pneumology and Thoracic Surgery, Grosshansdorf, Germany
Helgo Magnussen

Pulmonary Research Institute, Hospital Grosshansdorf Center for Pneumology and Thoracic Surgery,

Grosshansdorf, Germany

Correspondence to: Dr H Watz, Pulmonary Research Institute, Hospital Grosshansdorf, Center for Pneumology and Thoracic Surgery, Woehrendamm 80, D-22927 Grosshansdorf, Germany h.watz@pulmoresearch.de

doi: 10.1136/thx.2006.071811

*These authors contributed equally to this work.

Competing interests: None.

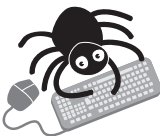

A supplementary table is available online at http:// www.thorax.bmi.com/ supplemental

\section{References}

Johnson SR. Lymphangioleiomyomatosis. Eur Respir J 2006;27:1056-65.

2 Goncharova EA, Goncharov DA, Spaits M, et al. Abnormal growth of smooth muscle-like cells in lymphangioleiomyomatosis: role for tumor suppressor TSC2. Am J Respir Cell Mol Biol 2006;34:561-72.

3 Crooks DM, Pacheco-Rodriguez G, Decastro RM, et al. Molecular and genetic analysis of disseminated neoplastic cells in lymphangioleiomyomatosis. Proc Natl Acad Sci USA 2004;101:17462-7.

4 Goncharova EA, Goncharov DA, Lim PN, et al. Modulation of cell migration and invasiveness by tumor suppressor TSC2 in lymphangioleiomyomatosis. Am J Respir Cell Mol Biol 2006;34:473-80.

5 Lesma E, Grande V, Carelli S, et al. Isolation and growth of smooth muscle-like cells derived from tuberous sclerosis complex- 2 human renal angiomyolipoma: epidermal growth factor is the required growth factor. Am J Pathol 2005; 167:1093-103

6 Matsui K, Beasley MB, Nelson WK, et al. Prognostic significance of pulmonary ymphangioleiomyomatosis histologic score. Am J Surg Pathol 2001;25:479-84. 